\title{
Discussion on Teaching about Heat-treatment of Steel Based on "Excellent Engineers Education Training Plan"
}

\author{
Wang Yuan, Li Wei, Wang Yingbiao, Zhu Daigen \\ College of Mechanical and Manufacturing Engineering, Southwest Forestry University \\ Kunming 650224, China
}

\begin{abstract}
In order to cultivate engineering consciousness, engineering quality and capacity of engineering practice for students, this paper designed a teaching method that involves the steel heat treatment teaching introduction, teaching thoughts, teaching contents and students confused knowledge based on " Excellent Engineers Education Training Plan ". Through years of the teaching practices, this method has obtained the desirable results; the student can use the knowledge to guide the practice for heat-treatment of steel, which has actively promoted the training of students in engineering practice ability.
\end{abstract}

Keywords-Excellent engineers; Heat-treatment of Steel; Discussion on Teaching; Engineering practice

\section{INTRODUCTION}

In order to better cultivate engineering consciousness, engineering quality and capacity of engineering practice for students, improve the quality of engineering education, cultivate outstanding engineers with practical and innovative ability [1-2], the Ministry of education in colleges and universities of China launched the " Excellent Engineers Education Training Plan (EEETP)" in June 2010 [3]. In this context, the majority of colleges and universities in China selected a number of professional as EEETP teaching demonstration point, for example, the mechanical design, manufacture and automation specialty of our school. After more than three years of teaching reform, the practical ability and innovative ability of students have been greatly improved.

"Heat-treatment of steel" is an important teaching content of "Mechanical Engineering Materials", "Engineering Materials and Machinery Manufacturing Foundation" or "Machinery Manufacturing Foundation" and so on. The course links key aspects of the major chapters of the "Fe-C alloy phase diagram" and "commonly used metallic materials". At the same time, this course can play a guiding role for the material selection and heat-treatment of parts such as gears, shafts and worms in the course of "Mechanical Design Basis" and the machining process establishment of parts such as case and machine base that the material is HT200 in the course of "Mechanical Manufacture Technology". The above courses are compulsory basic courses for mechanical engineering majors, closely related to engineering practice, and very practical [4-5]. They are also the theoretical foundation course and core curriculum of engineering training and innovation curriculum system [6-7]. Therefore, "heat-treatment of steel" is not only the key content of curriculum teaching, but also the basic content of guiding practical production and training engineering consciousness, engineering quality and capacity of engineering practice for students. Then, how to teach "heattreatment of steel" to obtained the desirable results, the author has accumulated years of teaching experience, and share with colleagues here.

\section{TEACHING INTRODUCTION}

Teaching introduction to a certain extent determines the quality of classroom teaching, good teaching introduction can stimulate students' interest in learning, and achieve twice the result with half the effort [8]. Then, under the EEETP, how to introduce teaching to stimulate students' interest in learning, and to apply the knowledge to the practice of instruction, is of great importance. Therefore, before the formal lecture, we start with some scenes of forging iron and sword (craftsmen took iron billet into flame furnace, removed when iron billet was heated to orange, then put it on the anvil repeatedly beat. The iron billet had been beat into a certain shape, into the furnace and then heated to orange, removed the blank, quickly added water cooling), and then lead to the opening of heat-treatment of steel. In addition, I took the two motorcycle sprockets (one of them had been badly worn and the other was slightly worn) and a file. Sprockets were made of the same material and worn by different manufacturers. Reciprocating filing with a file in the sprocket teeth, and asked the students to look at what happened. The students would find that the badly worn sprocket needed only a slight filing and it was observed that a bright part was exposed, while the lightly worn sprocket was difficult to reveal fresh light even if it was forcibly filed. At this point, ask the students question: "The two sprockets made of the same material. Why is one of them easy to file and cut while the other is difficult to file?" Here, students have interest in starting to study the heat-treatment of steel with blacksmith in rural, the ancient martial arts film in the swarm scene and a reflection of the problem. 


\section{TEACHING THOUGHT}

A good teaching thought will make the content of the chapters in depth and interlocking, stimulate students' desire for knowledge and achieve satisfactory teaching results [9]. The teaching content of "heat-treatment of steel" is generally located behind the teaching content of "Fe-C alloy phase diagram", and the contents of the two chapters are closely related. Therefore, in the formulation of teaching thought, we must first study to review the "Fe-C alloy phase diagram" of the relevant content. Such as the basic phases of $\mathrm{Fe}-\mathrm{C}$ alloy (ferrite, austenite and cementite), the basic organization (pearlite, Levin and low temperature Levin), the special points, lines and planes of the balance $\mathrm{Fe}-\mathrm{C}$ alloy phase diagram. Under the EEETP, we have formulated the following teaching thought: review relevant knowledge of $\mathrm{Fe}-\mathrm{C}$ alloy phase diagrams $\rightarrow$ microstructure transformation of steel during nonequilibrium heating $\rightarrow$ microstructure transformation of steel during non-equilibrium cooling $\rightarrow$ common heat treatment process of steel $\rightarrow$ practice teaching $\rightarrow$ surface heat treatment process of steel $\rightarrow$ heat treatment analysis of typical parts $\rightarrow$ chapter summary. Among them, when reviewing the relevant knowledge of $\mathrm{Fe}-\mathrm{C}$ alloy phase diagrams, particular emphasis should be placed on: the $\mathrm{Fe}-\mathrm{C}$ alloy phase diagram is a balanced alloy phase diagram. "Equilibrium" refers to the infinite slow heating and cooling of a phase diagram. However, in actual production, heating and cooling of steel are not infinitely slow, that is, non-equilibrium heating and cooling and the curves of heating and cooling are shown in Figure 1. The heating and cooling speed are expressed with an inclined straight line to indicate that the processes are finished at a faster speed.

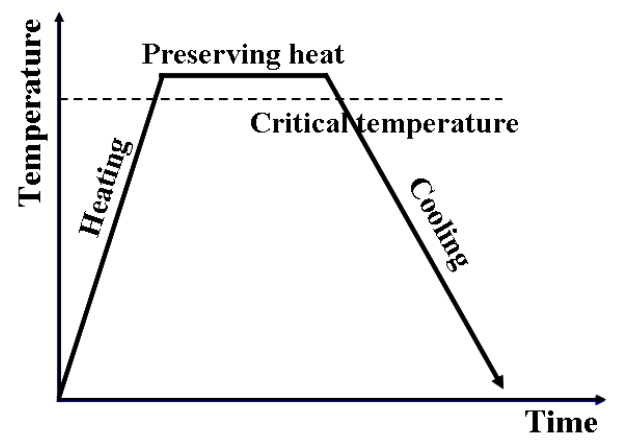

Fig. 1 The curve of heating and cooling for "heat-treatment of steel"

Naturally, the teaching content of "organizational transformation of steel in non-equilibrium heating and cooling" is naturally introduced to students. At the same time, it is emphasized that the ultimate structure and performance of heat treatment of steel depend on the cooling rate or cooling mode, which leads to the teaching content of the commonly used heat treatment process. That is, after the non-equilibrium heating structure changes, cooling is carried out in different cooling ways to obtain different structures and properties at room temperature. After the explanation of the teaching content of the common heat treatment process of steel, the training requirements for engineering consciousness, engineering quality and capacity of engineering practice of EEETP are put forward. Then arrange practical teaching content for students, guide practice with theory, and internalize and sublimate theoretical knowledge in practice. Next, interpret the heat treatment process of typical parts and the arrangement principle and function of each steps of the heat treatment process in the machining process. Finally, summarize and arrange the exercises after class, and connect the whole chapter with teaching content as a line of "teaching thought".

\section{TEACHING CONTENT SETTING}

The reasonable setting of the teaching content is a key factor to decide whether the training plan for the excellent engineer education should be fulfilled or not. Therefore, we have made a partial adjustment to the traditional teaching content of "heat treatment of steel ". Among them, the traditional teaching content of "heat treatment of steel" is mostly explained by the example of eutectoid steel [10-11]. The transformation of steel during non-equilibrium heating and cooling, and the two cooling curves, isothermal cooling and continuous cooling transformation curves, are also constructed and explained with eutectoid steel as a special case. This kind of explanation obviously cannot meet the requirements of production practice. Therefore, in this part of the teaching content, we have added the relevant teaching content of the heat treatment of hypo-eutectoid steel, hyper-eutectoid steel and part alloy steel, and the possible defects in the process of steel heat treatment. Only when the students master the relevant knowledge can they guide the practice with the theoretical knowledge they have learned. This lays a certain theoretical foundation for training engineering consciousness, engineering quality and capacity of engineering practice for students.

In practice teaching, the traditional teaching methods are mostly carried out by three kinds of tempering treatment, namely, low temperature, medium temperature and high temperature, after the 45 steels are quenched by water [12-13]. Obviously, the teaching method cannot meet the requirement of the training of engineering practice ability, which is emphasized in EEETP. Therefore, in practical teaching, we put the metallographic observation, hardness testing and heat treatment of steel three experiments together; students are required to complete the manufacture, observation and hardness test of the metallographic specimens of different steel grades before and after heat treatment. In heat treatment, four kinds of steel were selected: 20, T10, 20CrMnTi and 9SiCr. 20 and T10 respectively represent the hypo-eutectoid steels and hyper-eutectoid steels in carbon steels, while 20CrMnTi and $9 \mathrm{SiCr}$ respectively represent the low carbon alloy steels and high carbon alloy steels in alloy steels. Before the heat treatment experiment, students are required to consult the manual to determine the quenching temperature, cooling method and tempering temperature of the steel grades used. After the heat treatment experiment, students are required to prepare metallographic specimens and determine hardness of the steel grades under various heat treatments. Finish the related experiment of students, it is to give students the importance of content of carbon and alloy elements on the steel continuous cooling curve and its influence to the mobile steel continuous cooling curve, which is reflected in the heating temperature and cooling methods. In addition, the effect of 
carbon content, alloying elements and heat treatment on the microstructure of the steel is emphasized. Moreover, to emphasize the effects of carbon content, alloying elements and heat treatment methods on the hardness of the steel, the students were asked to associate the microstructure and hardness of the steel. Through the improved practice teaching, it has played a positive role in promoting students' engineering practice ability, and achieved the requirements of EEETP.

\section{EXPLANATION OF CONFUSING KNOWLEDGE POINTS}

\section{A. Austenitic phase}

For austenitic phase, they are explained in the "Fe-C alloy phase diagram" chapter as high temperature phase, and can only exist at high temperatures. But in the chapter of "heat treatment of steel", we also explain to students that when steel is quenched, the higher the content of carbon in the steel, the faster the cooling rate, and the higher the content of austenite in the room temperature, which makes the steel less rigid. The contents make students confused, why at room temperature, and the presence of austenite? At this point, we should give the students a detailed explanation. The phase diagram of the Fe-C alloy is a balanced phase diagram, which is measured at an infinite slow cooling rate. The austenite is a balanced high temperature phase. But in actual heat treatment, the austenite structure is not carried out at an infinitely slow cooling rate, but at a faster cooling rate (non-equilibrium cooling). At this time, some austenite does not have enough time to complete the lattice transformation and remains as the face centered cubic lattice is retained to room temperature, so the retained austenite in the actual heat treatment is a non-equilibrium phase. Thus, students have deepened understanding of the concepts of balance cooling and non-equilibrium cooling, balance phase and non-equilibrium phase.

\section{B. Isothermal cooling and continuous cooling}

For the concept of isothermal cooling and continuous cooling, students are also prone to confusion. The way we explain it to students as follows. Isothermal cooling is the transformation of a tissue for occurring and completing at constant temperature. Tissue transformation is independent of the cooling before and after the tissue transformation process. Rapid cooling at $\mathrm{Ar}_{1}$ temperature will result in rapid cooling of undercooled austenite to a certain temperature. During this cooling process, undercooling austenite does not undergo tissue transformation. Only in certain temperature of the process of insulation, undercooling austenite tissue transformation occurs, and adequate heat preservation time allows the tissue to complete the transformation. Once the tissue transformation has been completed, and it is quickly cooled to room temperature. Moreover, during the high temperature transition phase of isothermal transformation, for hypoeutectoid steel, undercooled austenite takes the lead to precipitate part of ferrite in the course of transformation. Thus, a line of ferrite is first detected on the transformation diagram, then unconverted undercooled austenite transforms into pearlite during the course of heat preservation, so the room temperature microstructure obtained by the hypoeutectoid steel at high temperature is $\mathrm{P}+\mathrm{F}$; for hyper-eutectoid steel, undercooled austenite takes the lead to precipitate part of $\mathrm{Fe}_{3} \mathrm{C}$ in the course of transformation. Therefore, a line of $\mathrm{Fe}_{3} \mathrm{C}$ is first detected on the transformation diagram, then unconverted undercooled austenite transforms into pearlite during the course of heat preservation, so the room temperature microstructure obtained by the hypoeutectoid steel at high temperature is $\mathrm{P}+\mathrm{Fe}_{3} \mathrm{C}$.

However, with the continuous cooling transformation, as long as half or martensite of cooling rate and cooling curves of continuous line start line-terminating line intersects, organization with the cooling process has been changed. Here, students should be emphasized that the isothermal cooling transition is at constant temperature, and that the continuous cooling transition is a transformation in the process of constantly lowering the temperature. With the continuous cooling transformation, as long as the upper/lower half or martensite of cooling rate and cooling curves of continuous line start line-terminating line intersects, organization with the cooling process has been changed. When the hypoeutectoid steel and hyper-eutectoid steel undergo high temperature transformation, some ferrite or $\mathrm{Fe}_{3} \mathrm{C}$ will be still precipitated first. If the cooling rate is between the upper critical cooling rate $v_{k}$ and the lower critical cooling rate $v_{k}^{\prime}$, when cooled to the pearlite transition stop line $K$, the undercooled austenite experiences a temporary cessation of transition. The remaining undercooled austenite begins to transform to martensite after further cooling to intersect the line Ms of martensite transformation. At this time, the transformation product of hypoeutectoid steel is $\mathrm{P}+\mathrm{F}+\mathrm{M}+\mathrm{A}$, and the transition product of hyper-eutectoid is $\mathrm{P}+\mathrm{Fe}_{3} \mathrm{C}+\mathrm{M}+\mathrm{A}$. The retained austenite is left because of the martensite which has not transformed completely.

After explaining the two conversion curves, the two transition curves are plotted in the transformation diagram shown in Figure 2, and the difference between the two is explained to the students. (1) The curve of continuous cooling (also named as CCT curve) is located below the curve of isothermal cooling (also named as TTT curve), undercooling austenite increases stability and transition time is longer; (2) There is no bainite transformation in CCT curve, only in TTT curve, and CCT curve is easy to determine; (3) CCT curve can better accurately reflects the relationship between cooling rate, transition temperature, time and product, and can be used to specify heat treatment process of steel.

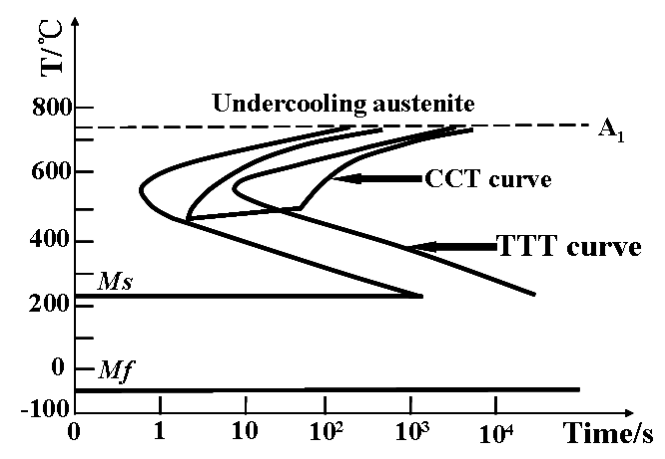

Fig. 2 The curve of CCT and TTT 
With the above of teaching about the concept of the isothermal cooling and continuous cooling, students should be emphasized again that the isothermal cooling transition is at constant temperature, and that the continuous cooling transition is a transformation in the process of constantly lowering the temperature. By explaining the relevant content, students are no longer unfamiliar with the steel's two cooling transition curve, but the skilled dungeon is in mind.

\section{Quenching degree and hardenability of steel}

For the two concepts of quenching degree and hardenability of steel, students are easily confused. The way we explain it to students as follows. Quenching degree refers to the ability of the hardened steel to obtain the tissue distance from the surface martensite to the internal semi martensite/semi non martensite under specified heat treatment conditions. If the distance is greater, the quenching degree of steel will be better, and vice versa. The hardenability of steel refers to the highest hardness of martensite after quenching. Hardness is related to the carbon content of the steel. If the carbon content is higher, the hardenability of steel will be greater, and vice versa. Here, it is emphasized that the quenching degree of steel is independent of hardness, depending on the chemical composition of the steel, and is an inherent property of the steel itself; Hardenability because of its "hard" word, so it is closely related to hardness, and related to heat treatment process, it depends mainly on the carbon content of steel, not the inherent nature of steel itself.

In the chapter of steel heat treatment, students are more likely to be confused. Because of the limitation of space, this article is no longer enumerated. Through the above explanation of students' confusing concepts, students can understand and distinguish relevant concepts. All of these have laid a solid foundation for the theory to guide practice and to train students' engineering practice ability.

\section{CONCLUSION}

"Heat treatment of steel" plays an important role in the fields of mechanical engineering, material and mechanical manufacturing, engineering and materials and mechanical manufacturing. It is essential knowledge for students to follow the course, study and pre repair, and it is also necessary knowledge for students to follow the design and development of mechanical products, select parts, heat treatment process and machining process arrangement. Therefore, the quality and effect of teaching will directly determine the quality of the students in the follow-up courses. Design of teaching introduction, teaching thought, teaching content setting and Explanation of confusing knowledge points based on EEETP. All of these make the teaching to achieve the desired teaching effect and lay a solid foundation for the cultivation of students' engineering consciousness, engineering quality and engineering practice ability.

\section{ACKNOWLEDGMENT}

The authors would like to acknowledge the financial support provided by the educational science research fund of Southwest Forestry University (Grant No. YB201629 and YB201627) and the construction fund of eight key industrial brand professionals in Yunnan Province (Grant No. 51600613).

\section{REFERENCES}

[1] Dan Yanping, Bao Qiuyan, Jiang Jibin. Reformation of undergraduate practice teaching system based on outstanding engineers training project [J]. Laboratory Science, 2011,6 : 213-215.

[2] Song Peiwei. Strengthen the reform of practice teaching and train excellent engineers $[\mathrm{J}]$. Heilongjiang Education(Higher Education Research \& Appraisal), 2011, 6:4-8.

[3] Wu Qidi. The problems and challenges of engineering education in China and research on engineering education [J]. Tsinghua Journal of Education, 2009, 2:4-8.

[4] Duan Pengyun, Wu Jian, Yao Shengwei, et al. Study and exploration for virtual simulation experiment teaching in mechanical engineering material [J]. Laboratory Science, 2016, 19(6):106-107

[5] Cao Xia. Study on the experimental teaching for the course of mechanical engineering materials based on the excellence initiative [J]. China Modern Educational Equipment, 2014, 19:69-71.

[6] Wang Yingbiao, Li Ming, Wang Yuan, et al. Discussion about Innovative Practical Teaching System for "Machinery Manufacturing Base" [J]. Forestry Machinery \& Woodworking Equipment, 2015, 43(8):48-50.

[7] Sun Kangning, Zhang Jingde, Fu Shuigen. Research on the Knowledge System of "Engineering materials and machinery manufacturing foundation"'[J]. China University Teaching, 2015, 5:63-66.

[8] Wang Yuan, Deng Ting-ting, Zhu Dai-gen. The teaching and reconsidering on "Mobility calculation for planar mechanisms" [J]. Journal of Machine Design, 2016, 33(S2):333-336

[9] Wang Yuan, Zhong Lihui, Wang Yingbiao, et al. Teaching and reconsidering on "transmission ratio calculation for gear Trains" [J]. Forestry Machinery \& Woodworking Equipment, 2016, 44(12):45-48

[10] Liang Yahong, Li Guowei, Wang Xiaohuan, et al. A tentative discussion of teaching method about theory of heat-treatment of steel course[J]. China Modern Educational Equipment, 2016, 4:71-72.

[11] Dong Lijun. Research and practice of exploratory teaching for the course of "mechanical engineering materials" [J]. Journal of Hunan Institute of Engineering, 26(2):95-99.

[12] Wang Zhigang, Xu Yong, Tian Bin, et al.Optimization and design of heat treatment of carbon steel in experimental teaching $[\mathrm{J}]$. Journal of Science of Teachers' College and University, 2014, 34(4):102-104.

[13] Li Hui. Teaching reform of mechanical engineering materials course[J]. Journal of Changzhou Institute of Technology, 2013, 26(3-4):90-93. 